\title{
Salicylanilide Diethyl Phosphates as Potential Inhibitors of Some Mycobacterial Enzymes
}

\author{
Martin Krátký, ${ }^{1}$ Eva Novotná, ${ }^{2}$ Shalini Saxena, ${ }^{3}$ Perumal Yogeeswari, ${ }^{3}$ \\ Dharmarajan Sriram, ${ }^{3}$ Markéta Švarcová, ${ }^{1}$ and Jarmila Vinšová ${ }^{1}$ \\ ${ }^{1}$ Department of Inorganic and Organic Chemistry, Faculty of Pharmacy, Charles University in Prague, \\ Heyrovského 1203, 50005 Hradec Králové, Czech Republic \\ ${ }^{2}$ Department of Biochemical Sciences, Faculty of Pharmacy, Charles University in Prague, Heyrovského 1203, \\ 50005 Hradec Králové, Czech Republic \\ ${ }^{3}$ Medicinal Chemistry Research Laboratory, Pharmacy Group, Birla Institute of Technology and Science, Hyderabad 500078, India
}

Correspondence should be addressed to Jarmila Vinšová; vinsova@faf.cuni.cz

Received 24 July 2014; Accepted 26 September 2014; Published 4 November 2014

Academic Editor: Andrei Surguchov

Copyright (C) 2014 Martin Krátký et al. This is an open access article distributed under the Creative Commons Attribution License, which permits unrestricted use, distribution, and reproduction in any medium, provided the original work is properly cited.

\begin{abstract}
Antimycobacterially active salicylanilide diethyl phosphates were evaluated to identify their potential drug target(s) for the inhibition of several mycobacterial enzymes, including isocitrate lyase, L-alanine dehydrogenase ( $M t \mathrm{AlaDH})$, lysine $\varepsilon$-aminotransferase, chorismate mutase, and pantothenate synthetase. The enzymes are related to the nongrowing state of Mycobacterium tuberculosis. Salicylanilide diethyl phosphates represent new candidates with significant inhibitory activity especially against L-alanine dehydrogenase. The most active $M t$ AlaDH inhibitor, 5-chloro-2-[(3-chlorophenyl)carbamoyl]phenyl diethyl phosphate, has an $\mathrm{IC}_{50}$ of $4.96 \mu \mathrm{M}$ and the best docking results. Other mycobacterial enzymes were mostly inhibited by some derivatives but at higher concentrations; isocitrate lyase showed the highest resistance to salicylanilide diethyl phosphates.
\end{abstract}

\section{Introduction}

The increased number of drug-resistant tuberculosis (TB) cases worldwide and the evidence of recently reported totally drug-resistant strains demonstrate the urgent need for novel therapeutic interventions [1] including innovative antimycobacterial drugs with no cross-resistance to clinically used drugs.

Recently, salicylanilide diethyl phosphates (diethyl [(2phenylcarbamoyl)phenyl] phosphates 1; Figure 1) have been synthesized as potential antimycobacterial agents with activity in the micromolar range (minimum inhibitory concentrations (MICs) from $1 \mu \mathrm{M}$ ). They inhibit nontuberculous mycobacteria and both drug-susceptible and drug-resistant Mycobacterium tuberculosis (Mtb) strains [2]. Previously, some salicylanilide-based derivatives were reported as mild inhibitors of mycobacterial isocitrate lyase (ICL) and methionine aminopeptidase [3]. The exact mechanism(s) of their action as antimicrobial agents has still not been fully elucidated. Therefore, we screened the presented derivatives for new enzymatic targets of $M t b$, especially those related to the nongrowing state. No inhibitor of the selected enzymes has been established for clinical practice to date.

Mycobacterium tuberculosis exhibits a tendency to remain latent or persistent for decades before its activation into symptomatic disease. The bacterium has developed ingenious mechanisms to survive inside a hostile environment and to acquire essential nutrients. These metabolic processes appear to provide potential targets for novel anti-TB agents [4]. Genetic analysis has revealed a set of new potential drug targets in $M t b$.

Isocitrate lyase (ICL; EC 4.1.3.1) is one of two enzymes comprising the glyoxylate shunt and splits isocitrate into succinate and glyoxylate; this metabolic pathway is absent in vertebrates. ICL is responsible for the persistence of $M t b$ and, additionally, disruption of the icl gene attenuated 


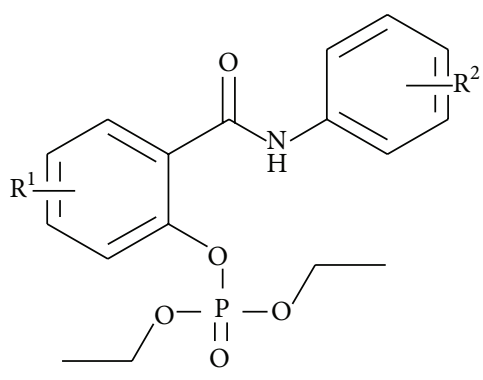

FIgURE 1: General structure of salicylanilide diethyl phosphates 1 (diethyl [2-(phenylcarbamoyl)phenyl] phosphates; $\mathrm{R}^{1}=4-\mathrm{Cl}, 5-\mathrm{Cl}$, $\left.4-\mathrm{Br} ; \mathrm{R}^{2}=3-\mathrm{Cl}, 4-\mathrm{Cl}, 3,4-\mathrm{diCl}, 3-\mathrm{Br}, 4-\mathrm{Br}, 3-\mathrm{F}, 4-\mathrm{F}, 3-\mathrm{CF}_{3}, 4-\mathrm{CF}_{3}\right)$.

TABLE 1: ICL inhibition activity of selected salicylanilide diethyl phosphates 1.

\begin{tabular}{lccc}
\hline & $\mathrm{R}^{1}$ & $\mathrm{R}^{2}$ & $\begin{array}{c}\text { \% ICL inhibition at } 10 \mu \mathrm{M} \\
( \pm \text { standard deviation })\end{array}$ \\
\hline $\mathbf{l a}$ & $4-\mathrm{Br}$ & $3-\mathrm{F}$ & $7 \pm 2.45$ \\
$\mathbf{l h}$ & $4-\mathrm{Br}$ & $4-\mathrm{Br}$ & $6 \pm 2.41$ \\
$\mathbf{1 s}$ & $5-\mathrm{Cl}$ & $3-\mathrm{Cl}$ & $6 \pm 0.83$ \\
$\mathbf{l u}$ & $5-\mathrm{Cl}$ & $3-\mathrm{F}$ & $4 \pm 0.50$ \\
$\mathbf{l v}$ & $5-\mathrm{Cl}$ & $4-\mathrm{F}$ & $6 \pm 0.92$ \\
$\mathbf{1 w}$ & $5-\mathrm{Cl}$ & $4-\mathrm{Br}$ & $6 \pm 1.00$ \\
$\mathbf{1 x}$ & $5-\mathrm{Cl}$ & $4-\mathrm{Cl}$ & $6 \pm 1.31$ \\
\hline \multicolumn{3}{c}{ 3-Nitropropionic acid } & $25 \pm 4.1$ \\
\multicolumn{3}{c}{ Isoniazid } & 0 \\
\hline
\end{tabular}

Esters, which are not reported here, had no ICL inhibition.

bacterial virulence and adaptation to hypoxia [3]. Based on the fact that salicylanilides and their esters with various acids have been reported as isocitrate lyase inhibitors $[3,5]$, we evaluated salicylanilide diethyl phosphates $\mathbf{1}$ against this enzyme (Table 1).

The mycobacterial L-alanine dehydrogenase $(M t \mathrm{AlaDH}$; EC 1.4.1.1) catalyzes the NADH-dependent reversible oxidative deamination of $\mathrm{L}$-alanine to pyruvate and ammonia [6]. Both L-alanine and D-alanine are important components of peptidoglycan. MtAlaDH plays a key role in the utilisation of carbon and nitrogen sources. It was observed that in the persistent state of the microorganism the gene coding $M t \mathrm{AlaDH}$ is upregulated $[7,8]$.

Lysine $\varepsilon$-aminotransferase (MtLAT; EC 2.6.1.36) has been implicated in the mycobacterial stress response and is upregulated by approximately 40 -fold in nutrient-starved models designed to mimic the persistent/latent state of TB [9]. MtLAT also plays an important role in adaptation to long-term persistence in $M t b$ [10]. In addition, this enzyme has been shown to be upregulated during adaptation to the stationary phase and low-oxygen dormancy [11].

Chorismate mutase (MtCM; EC 5.4.99.5) is another promising selective drug target [12]. This enzyme catalyzes the Claisen rearrangement of chorismate to prephenate in the shikimate pathway, which is the first committed step in the biosynthesis of the aromatic amino acids phenylalanine and tyrosine.
Pantothenate synthetase (MtPS; EC 6.3.2.1) catalyzes the essential adenosine triphosphate-dependent condensation of $D$-pantoate and $\beta$-alanine to form pantothenate in bacteria, yeast, and plants. Pantothenate is a key precursor for the biosynthesis of coenzyme A and acyl carrier protein, which are essential cofactors for bacterial growth $[13,14]$.

We evaluated salicylanilide diethyl phosphates $\mathbf{1}$ also against these four mycobacterial persistence-related enzymes as a pilot screening.

\section{Materials and Methods}

2.1. Chemistry. The synthesis and characterization of the salicylanilide diethyl phosphates were published previously [2]. Yield of esters synthesized via reaction of parent salicylanilides with diethyl chlorophosphate in the presence of triethylamine ranged from $11 \%$ up to $78 \%$.

\subsection{Enzyme Inhibition Measurement}

2.2.1. Isocitrate Lyase Assay (ICL1). Isocitrate lyase activity was assayed according to the protocol reported by Dixon and Kornberg (glyoxylate phenyl hydrazone formation) [15] at $10 \mu \mathrm{M}$ of the investigated compounds. Isoniazid was employed as a negative control (inhibition of $0 \%$ ), and 3nitropropionic acid (3-NP) served as a positive control. A description of the method can be found in the literature [5].

\subsubsection{Mycobacterial L-Alanine Dehydrogenase (MtAlaDH)} [16] Assay. A reaction mixture consisting of $125 \mathrm{mM}$ glycine $/ \mathrm{KOH}$ (pH 10.2), $100 \mathrm{mM}$ L-alanine, $1.25 \mathrm{mM} \mathrm{NAD}^{+}$, and $6.026 \mathrm{pM}$ of $M t \mathrm{AlaDH}$ in a final volume of $200 \mu \mathrm{L}$ diluted in $125 \mathrm{mM}$ glycine/KOH ( $\mathrm{pH} 10.2$ ) was added to each well of a 96-well plate. The compounds were then added to the plates. The reaction was initiated by the addition of $10 \mu \mathrm{L}$ enzyme diluted in buffer. Enzymatic activity was measured by the rate of production of NADH that accompanies the conversion of alanine to pyruvate by oxidative deamination [17]. The reaction components, except for $M t A l a D H$, were mixed in the well and the background reaction was measured; $M t \mathrm{AlaDH}$ was then added and the reaction kinetics were monitored. All measurements were performed at $340 \mathrm{~nm}$ with a heat-controlled Perkin Elmer Victor V3 spectrophotometer.

2.2.3. Mycobacterial Lysine $\varepsilon$-Aminotransferase (MtLAT) [18] Assay. The reaction mixture consisting of $1 \mathrm{mM}$ L-lysine $\mathrm{HCl}, 1 \mathrm{mM} \alpha$-ketoglutarate, $15 \mu \mathrm{M}$ pyridoxal- $5^{\prime}$-phosphate, and $1.25 \mathrm{pM} \mathrm{MtLAT}$ in a final volume of $200 \mu \mathrm{L}$ diluted in $200 \mathrm{mM}$ phosphate buffer ( $\mathrm{pH} 7.2$ ) was added to each well of a 96-well plate. Compounds were then added to the plates. The reaction was initiated by the addition of $10 \mu \mathrm{L}$ of $M t \mathrm{LAT}$, diluted in buffer. The mixture was incubated at $37^{\circ} \mathrm{C}$ for $1 \mathrm{~h}$. The reaction was terminated by the addition of $10 \%$ trichloroacetic acid in ethanol. Piperideine 6-carboxylate (P6C) was detected by measuring the colour intensity of its adduct with 2 -aminobenzaldehyde spectroscopically at $465 \mathrm{~nm}$. The reaction components except for $M t \mathrm{LAT}$ were 
mixed in the well and the background reaction was measured; $M t$ LAT was then added and the reaction kinetics were monitored. Reactions were carried out at $37^{\circ} \mathrm{C}$ in a heatcontrolled Perkin Elmer Victor V3 spectrophotometer.

One LAT unit $(1 \mathrm{U})$ is the activity that produces $1 \mu \mathrm{M}$ of P6C per min under these conditions.

\subsubsection{Mycobacterial Chorismate Mutase (MtCM) [19] Assay.} Reaction volumes of $0.4 \mathrm{~mL}$ of chorismate (typically $1 \mathrm{mM}$ ) in $50 \mathrm{mM}$ Tris $\mathrm{HCl}$ ( $\mathrm{pH} 7.5), 0.5 \mathrm{mM}$ EDTA, $0.1 \mathrm{mg} / \mathrm{mL}$ bovine serum albumin, and $10 \mathrm{mM} \beta$-mercaptoethanol were incubated at $37^{\circ} \mathrm{C}$ for $5 \mathrm{~min}$. The reaction was started with the addition of $10 \mu \mathrm{L} 5 \mathrm{pM}$ of $M t \mathrm{CM}$ (i.e., $185 \mathrm{ng}$ of $M t \mathrm{CM}$ equivalent to $12.5 \mathrm{nM}$ final concentration of the dimer based on the molecular mass of $36,948 \mathrm{Da}$ ). The reaction was allowed to proceed at $37^{\circ} \mathrm{C}$ and was terminated after 1 to $5 \mathrm{~min}$ with $0.4 \mathrm{~mL} 1 \mathrm{M} \mathrm{HCl}$. After a further incubation at $37^{\circ} \mathrm{C}$ for $10 \mathrm{~min}$ to convert prephenate, which is formed in the enzymatic reaction, to phenylpyruvate, $0.8 \mathrm{~mL} 2.5 \mathrm{M} \mathrm{NaOH}$ was added. The absorbance of the phenylpyruvate chromophore was read at $320 \mathrm{~nm}$. We set up a blank with no enzyme for every reaction to account for the nonenzymatic conversion of chorismate to prephenate and added the enzyme after the addition of $\mathrm{NaOH}$. The absorbance at $320 \mathrm{~nm}$ for the blank varied from 0.1 to 0.3 , depending on the concentration of chorismate and the duration of the reaction. A description of the methods can be found in the literature [19].

2.2.5. Mycobacterial Pantothenate Synthetase (MtPS) Screening $[20,21]$. Sixty microliters of the PS reagent mix was added, including NADH, pantoic acid, $\beta$-alanine, ATP, phosphoenolpyruvate, $\mathrm{MgCl}_{2}$, myokinase, pyruvate kinase, and lactate dehydrogenase in buffer, to each well of a 96-well plate. The compounds were then added to plates in $1 \mu \mathrm{L}$ volumes. The reaction was initiated by the addition of $39 \mu \mathrm{L}$ PS diluted in buffer. The final concentrations in the reaction were $0.4 \mathrm{mM} \mathrm{NADH}, 5 \mathrm{mM}$ pantoic acid, $10 \mathrm{mM} \mathrm{MgCl}_{2}, 5 \mathrm{mM} \beta$ alanine, $10 \mathrm{mM}$ ATP, $1 \mathrm{mM}$ potassium phosphoenolpyruvate, and 18 units $/ \mathrm{mL}$ each of chicken muscle myokinase, rabbit muscle pyruvate kinase, and rabbit muscle lactate dehydrogenase diluted in $100 \mathrm{mM}$ HEPES buffer ( $\mathrm{pH} 7.8$ ), 1\% DMSO, and $5 \mu \mathrm{g} / \mathrm{mL}$ PS in a final volume of $100 \mu \mathrm{L}$. The test plate was immediately transferred to a microplate reader, and absorbance was measured at $340 \mathrm{~nm}$ every $12 \mathrm{sec}$ for $120 \mathrm{sec}$. Each plate had 16 control wells in the two outside columns, of which 12 contained the complete reaction mixture with a DMSO carrier control (full reaction) and four did not have PS added (background). The per cent inhibition was calculated using the following formula: $100 * 1$ - compound rate background rate/full reaction rate - background rate.

2.3. Molecular Docking Studies. The crystal structure of $M t A l a D H$ was obtained from the Protein Data Bank (http://www.pdb.org/, pdb code 2VHW). Water molecules and $\mathrm{NAD}^{+}$were removed, polar hydrogens were added, partial charges were assigned, and the energy of the molecule was minimised using UCSF Chimera software 1.6.2. [22]. The ligand structure was created using CS ChemOffice version 10.0
(CambridgeSoft), and its conformation optimised with the aid of UCSF Chimera 1.6.2 using the Amber force field.

Docking calculations were carried out using Autodock Vina [23]. The three-dimensional affinity grid box was designed to include the full active site of $M t \mathrm{AlaDH}$ (box centre: $x=-58, y=57$, and $z=8$; size of the box 20 points in each direction). The enzyme structure was kept rigid during the docking procedure. The visualisation of enzyme-ligand interactions was prepared using PyMol 1.1r1. [24].

\section{Results and Discussion}

With respect to isocitrate inhibition, most of the evaluated compounds 1 were inactive at the concentration of $10 \mu \mathrm{M}$; some of these molecules displayed the ability to activate the tested enzyme. Only seven derivatives showed very weak inhibition, within the range from 4 to $7 \%$, but without any significant activity. It seems that only halogen monosubstitution of the aniline ring and the presence of 4-bromo or 5-chloro substitution on the salicylic ring retain some inhibitory activity. Salicylanilide diethyl phosphates 1 failed with respect to finding more efficient ICL inhibitors and when compared with previously described esters $[3,5]$. The low inhibition rates observed for these phosphate esters 1 indicate the importance of the acid used for the esterification of parent salicylanilides in the inhibition results.

To explore other possible target(s) of derivatives $\mathbf{1}$, the inhibitory activity at $50 \mu \mathrm{M}$ was screened against four other mycobacterial enzymes, MtAlaDH, MtLAT, MtCM, and $M t P S$ (Table 2), which play very important roles in $M t b$ persistence. The investigated compounds showed weak activity against MtPS (the highest activity was approximately $26 \%$ for 1r) and MtLAT, where only compound ls showed inhibition higher than 50\%. More than 50\% inhibitory activity against $M t \mathrm{CM}$ was found for thirteen compounds, with the highest in vitro efficacy for compounds 10 and 1 s (above 60\%). The highest percentage activity was found for inhibition of $\mathrm{MtAlaDH}$; compounds $\mathbf{1 s ,} \mathbf{1 q}$, and $\mathbf{1 n}$ had more than $70 \%$ inhibition. Therefore, their $\mathrm{IC}_{50}$ values were determined and are reported in Table 2. We plotted the graphs of the inhibition rates [\%] of $50,25,12.5,6.25,3.13$, and $1.56 \mu \mathrm{M}$ and calculated $\mathrm{IC}_{50}$ values. 5-Chloro-2-[(3-chlorophenyl)carbamoyl]phenyl diethyl phosphate, 1s, was found to be the most potent compound against $\mathrm{MtAlaDH}$ with an $\mathrm{IC}_{50}$ of $4.96 \mu \mathrm{M}$. Interestingly, this molecule also exhibited superior inhibition of MtLAT and $M t C M$, as pointed previously. Its MICs against actively growing $M t b \mathrm{H}_{37} \mathrm{Rv}$ strain were $4-8 \mu \mathrm{M}$ [2].

Based on the inhibition results, the whole series of salicylanilide diethyl phosphates $\mathbf{1}$ was investigated in a molecular docking study to identify possible interactions with amino acid residues in the active site of $\mathrm{MtAlaDH}$. The three-dimensional structure of native $M t \mathrm{AlaDH}$ is described as a hexamer formed by three associated dimers of protein subunits. Each subunit consists of two distinct domains, the substrate-binding domain (residues 1-129 and 311-370) and the $\mathrm{NAD}^{+} / \mathrm{NADH}$ binding domain (residues 130-310). These domains are separated from each other by a cleft in which most of the active site amino acid residues are located [16]. 
TABLE 2: Mycobacterial enzyme activity inhibition results.

\begin{tabular}{|c|c|c|c|c|c|c|c|}
\hline $\begin{array}{l}\text { Comp. } \\
\text { code }\end{array}$ & $\mathrm{R}^{1}$ & $\mathrm{R}^{2}$ & $\begin{array}{c}\text { \% inhibition at } \\
50 \mu \mathrm{M} \text { against } \\
\mathrm{L}-\mathrm{M} t \mathrm{AlaDH}\end{array}$ & $\begin{array}{c}\mathrm{L}-M t \text { AlaDH } \\
\mathrm{IC}_{50}(\mu \mathrm{M})\end{array}$ & $\begin{array}{c}\% \text { inhibition at } \\
50 \mu \mathrm{M} \text { against } \\
M t \mathrm{LAT}\end{array}$ & $\begin{array}{c}\text { \% inhibition at } \\
50 \mu \mathrm{M} \text { against } \\
M t \mathrm{CM}\end{array}$ & $\begin{array}{c}\% \text { inhibition at } \\
50 \mu \mathrm{M} \text { against } \\
M t \mathrm{PS}\end{array}$ \\
\hline 1a & $4-\mathrm{Br}$ & $3-F$ & 69.94 & 39.75 & 7.80 & 40.50 & 7.47 \\
\hline $1 b$ & $4-\mathrm{Br}$ & $3-\mathrm{Cl}$ & 59.46 & 41.12 & 18.73 & 43.50 & 3.89 \\
\hline $1 c$ & $4-\mathrm{Br}$ & $4-\mathrm{Cl}$ & 39.35 & $>50$ & 29.10 & 48.31 & 13.25 \\
\hline 1d & $4-\mathrm{Br}$ & 3,4 -di-Cl & 59.02 & 31.92 & 30.27 & 41.30 & 20.54 \\
\hline le & $4-\mathrm{Br}$ & $3-\mathrm{CF}_{3}$ & 42.08 & $>50$ & 40.20 & 53.20 & 17.76 \\
\hline lf & $4-\mathrm{Br}$ & $4-\mathrm{CF}_{3}$ & 69.28 & 34.73 & 26.15 & 52.09 & 11.33 \\
\hline $1 \mathrm{~g}$ & $4-\mathrm{Br}$ & $3-\mathrm{Br}$ & 22.62 & $>50$ & 12.42 & 46.07 & 18.76 \\
\hline lh & $4-\mathrm{Br}$ & $4-\mathrm{Br}$ & 34.35 & $>50$ & 18.25 & 38.19 & 18.33 \\
\hline li & $4-\mathrm{Br}$ & $4-\mathrm{F}$ & 54.58 & 15.58 & 2.90 & 46.67 & 5.41 \\
\hline $\mathbf{l j}$ & $4-\mathrm{Cl}$ & $3-\mathrm{Cl}$ & 12.30 & $>50$ & 29.30 & 54.56 & 3.64 \\
\hline $1 \mathbf{k}$ & $4-\mathrm{Cl}$ & $4-\mathrm{Cl}$ & 18.73 & $>50$ & 38.00 & 43.78 & 14.74 \\
\hline 11 & $4-\mathrm{Cl}$ & $3-F$ & 61.87 & 23.11 & 8.06 & 50.75 & 17.93 \\
\hline $1 \mathrm{~m}$ & $4-\mathrm{Cl}$ & $4-\mathrm{F}$ & 57.70 & 42.26 & 20.12 & 49.33 & 7.76 \\
\hline ln & $4-\mathrm{Cl}$ & $4-\mathrm{Br}$ & 70.64 & 29.17 & 17.29 & 50.19 & 6.57 \\
\hline 10 & $4-\mathrm{Cl}$ & 3,4-di-Cl & 44.46 & $>50$ & 18.24 & 60.96 & 23.01 \\
\hline $1 p$ & $4-\mathrm{Cl}$ & $3-\mathrm{Br}$ & 54.64 & 36.11 & 19.13 & 37.41 & 20.59 \\
\hline $1 q$ & $4-\mathrm{Cl}$ & $3-\mathrm{CF}_{3}$ & 73.88 & 36.32 & 19.05 & 50.02 & 11.53 \\
\hline $1 \mathrm{r}$ & $4-\mathrm{Cl}$ & $4-\mathrm{CF}_{3}$ & 47.28 & $>50$ & 23.18 & 50.05 & 26.25 \\
\hline 1s & $5-\mathrm{Cl}$ & $3-\mathrm{Cl}$ & 73.94 & 4.96 & 53.64 & 60.12 & 11.18 \\
\hline 1t & $5-\mathrm{Cl}$ & $3-\mathrm{Br}$ & 41.51 & $>50$ & 12.86 & 57.58 & 5.04 \\
\hline $\mathbf{l u}$ & $5-\mathrm{Cl}$ & $3-\mathrm{F}$ & 59.85 & 39.20 & 23.42 & 52.36 & 22.22 \\
\hline $1 \mathrm{v}$ & $5-\mathrm{Cl}$ & $4-\mathrm{F}$ & 69.07 & 34.47 & 37.29 & 52.05 & 17.28 \\
\hline $1 w$ & $5-\mathrm{Cl}$ & $4-\mathrm{Br}$ & 14.97 & $>50$ & 40.28 & 52.84 & 14.51 \\
\hline $1 x$ & $5-\mathrm{Cl}$ & $4-\mathrm{Cl}$ & 58.62 & 46.51 & 20.18 & 53.79 & 11.17 \\
\hline $1 y$ & $5-\mathrm{Cl}$ & 3,4-di-Cl & 26.30 & $>50$ & 28.17 & 56.65 & 12.38 \\
\hline $1 z$ & $5-\mathrm{Cl}$ & $3-\mathrm{CF}_{3}$ & 58.32 & 17.82 & 10.01 & 43.49 & 4.51 \\
\hline $1 z z$ & $5-\mathrm{Cl}$ & $4-\mathrm{CF}_{3}$ & 64.82 & 37.49 & 19.83 & 54.09 & 8.26 \\
\hline
\end{tabular}

The best results for each enzyme are shown in bold.

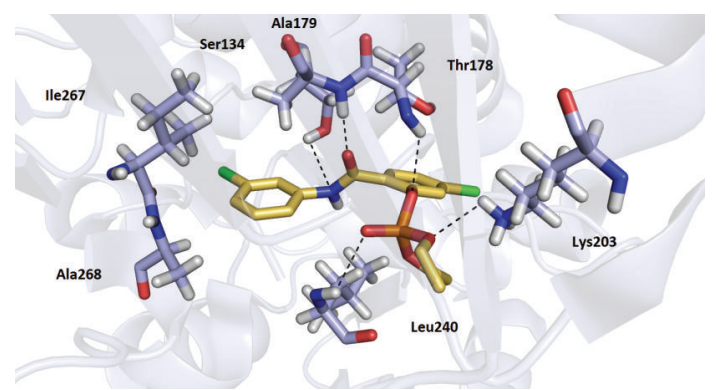

FIGURE 2: Molecular docking of the 1s derivative with H-bonds and hydrophobic interactions with amino acid residues of $\mathrm{MtAlaDH}$.

The top-scoring orientations of the compounds were located in the cavity normally occupied by $\mathrm{NAD}^{+}$(Figure 2 ). All of the compounds in the series displayed a similar conformation in the active site. Since structural differences of the compounds 1 are very small, the docking studies enabled us only to predict possible orientation in the active site of the enzyme, but the influence of different position of substitution on the activity is not clear. In general, the orientation of all of the compounds suggests possible $\mathrm{H}$-bond interactions, predominantly with two amino acid residues, Thr178 and Ala179. In addition, some of the compounds showed another H-bond interaction with Ala238, Leu240, Ser134, and Lys203. The most active compound in the series, 5-chloro2-[(3-chlorophenyl)carbamoyl]phenyl diethyl phosphate 1s $\left(\mathrm{IC}_{50} 4.96 \mu \mathrm{M}\right)$, exhibited $\mathrm{H}$-bond interactions with residues Ser134, Thr178, Ala179, Lys203, and Leu240 and additional hydrophobic interactions with amino acid residues Ile267 and Ala268 (Figure 2), which resulted in one of the highest affinities for the enzyme (docking score $-7.8 \mathrm{~kJ} / \mathrm{mol}$ ). Good docking results were also observed for compounds with a trifluoromethyl substitution in the aniline part $(\mathbf{l e}, \mathbf{l f}, \mathbf{1 q}, \mathbf{1 r}, \mathbf{1 z}$, and $\mathbf{1 z z}$ ). These compounds demonstrated the same H-bond interactions as 1s. Additionally, the trifluoromethyl group is positioned in a small cavity occupied by hydrophobic amino acid residues (Leu130, Ala137, and Ile267), and the potential to form hydrophobic interactions may cause a higher binding 


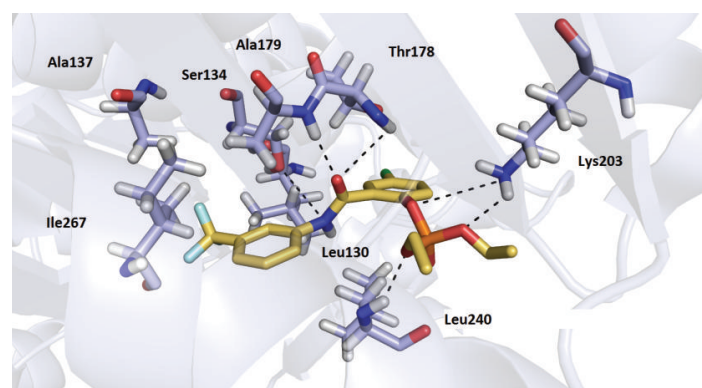

FIgURE 3: Molecular docking of the $\mathbf{1 q}$ derivative with trifluoromethyl group pointing into hydrophobic cavity comprising residues Leu130, Ala137, and Ile267.

affinity of these derivatives for the enzyme (Figure 3). However, another mechanism of the salicylanilide action may participate together with inhibition of $M t \mathrm{AlaDH}$.

We have found that there is not a direct relationship of in vitro MICs of salicylanilide diethyl phosphates against actively growing $M t b$ and the inhibition of five presented enzymes, especially when the suppression of these enzymes should affect especially persistent mycobacterial subpopulation. The results confirm the fact that salicylanilide derivatives share a complex mechanism of action with more molecular/cellular targets.

\section{Conclusions}

To identify potential TB drug target(s) of salicylanilide diethyl phosphates, they were evaluated against five mycobacterial enzymes related to dormancy. Most of the compounds exhibited significant inhibition, especially against $M t \mathrm{AlaDH}$ with $\mathrm{IC}_{50}$ of $4.96 \mu \mathrm{M}$ or higher. Additionally, MtLAT and $M t \mathrm{CM}$ were affected considerably by diethyl phosphates. Salicylanilide derivatives have multiple mechanism of action and the activity against these enzymes only contributes to their antimycobacterial activity. There is no clear correlation between MICs against actively growing M. tuberculosis and inhibition of enzymes, which are important predominantly or exclusively for persistent state.

Our data represent the results of enzyme inhibition screening. Further studies to verify that these compounds are true inhibitors of $\mathrm{MtAlaDH}$ are required (e.g., inducing drugresistant mutants and identification of possible mutations, cocrystallisation of the enzyme with an inhibitor, etc.). Based on structural similarity, related and analogous derivatives may be designed and evaluated as prospective inhibitors of this enzyme.

\section{Conflict of Interests}

The authors declare that there is no conflict of interests regarding the publication of this paper.

\section{Acknowledgments}

The work was financially supported by the Research project IGA NT 13346 (2012). This paper is a result of the project implementation: "Support of Establishment, Development, and Mobility of Quality Research Teams at the Charles University," Project no. CZ.1.07/2.3.00/30.0022, supported by The Education for Competitiveness Operational Programme (ECOP) and cofinanced by the European Social Fund and the state budget of the Czech Republic. The paper is cofinanced by the European Social Fund and the state budget of the Czech Republic Project no. CZ.1.07/2.3.00/20.0235, the title of the project: TEAB. The authors want to thank J. Urbanová, M.A., for the language help.

\section{References}

[1] B. Saifullah, P. Arulselvan, M. E. El Zowalaty et al., "Development of a highly biocompatible antituberculosis nanodelivery formulation based on para-aminosalicylic acid-zinc layered hydroxide nanocomposites," The Scientific World Journal, vol. 2014, Article ID 401460, 12 pages, 2014.

[2] J. Vinšová, J. Kozic, M. Krátký et al., "Salicylanilide diethyl phosphates: synthesis, antimicrobial activity and cytotoxicity," Bioorganic and Medicinal Chemistry, vol. 22, no. 2, pp. 728-737, 2014.

[3] M. Krátký, J. Vinšová, E. Novotná et al., "Salicylanilide derivatives block Mycobacterium tuberculosis through inhibition of isocitrate lyase and methionine aminopeptidase," Tuberculosis, vol. 92, no. 5, pp. 434-439, 2012.

[4] S. K. Hatzios and C. R. Bertozzi, "The regulation of sulfur metabolism in Mycobacterium tuberculosis," PLoS Pathogens, vol. 7, no. 7, Article ID e1002036, 8 pages, 2011.

[5] M. Krátký, J. Vinšová, E. Novotná, J. Mandíková, F. Trejtnar, and J. Stolaříková, "Antibacterial activity of salicylanilide 4(trifluoromethyl)benzoates," Molecules, vol. 18, no. 4, pp. 36743688, 2013.

[6] A. B. Andersen, P. Andersen, and L. Ljungqvist, "Structure and function of a 40,000-molecular-weight protein antigen of Mycobacterium tuberculosis," Infection and Immunity, vol. 60, no. 6, pp. 2317-2323, 1992.

[7] Z. Y. Feng, N. E. Cáceres, G. Sarath, and R. G. Barletta, "Mycobacterium smegmatis L-alanine dehydrogenase (Ald) is required for proficient utilization of alanine as a sole nitrogen source and sustained anaerobic growth," Journal of Bacteriology, vol. 184, no. 18, pp. 5001-5010, 2002.

[8] B. Ling, M. Sun, S. Bi, Z. Jing, and Y. Liu, "Molecular dynamics simulations of the coenzyme induced conformational changes of Mycobacterium tuberculosis L-alanine dehydrogenase," Journal of Molecular Graphics and Modelling, vol. 35, pp. 1-10, 2012.

[9] J. C. Betts, P. T. Lukey, L. C. Robb, R. A. McAdam, and K. Duncan, "Evaluation of a nutrient starvation model of Mycobacterium tuberculosis persistence by gene and protein expression profiling," Molecular Microbiology, vol. 43, no. 3, pp. 717-731, 2002.

[10] D. Dube, S. M. Tripathi, and R. Ramachandran, "Identification of in vitro inhibitors of Mycobacterium tuberculosis Lysine $\varepsilon$-aminotransferase by pharmacophore mapping and threedimensional flexible searches," Medicinal Chemistry Research, vol. 17, no. 2-7, pp. 182-188, 2008.

[11] M. I. Voskuil, K. C. Visconti, and G. K. Schoolnik, “Mycobacterium tuberculosis gene expression during adaptation to stationary phase and low-oxygen dormancy," Tuberculosis, vol. 84, no. 3-4, pp. 218-227, 2004. 
[12] M. Ökvist, R. Dey, S. Sasso, E. Grahn, P. Kast, and U. Krengel, "1.6 $\AA$ crystal structure of the secreted chorismate mutase from Mycobacterium tuberculosis: novel fold topology revealed," Journal of Molecular Biology, vol. 357, no. 5, pp. 1483-1499, 2006.

[13] E. L. White, K. Southworth, L. Ross et al., "A novel inhibitor of Mycobacterium tuberculosis pantothenate synthetase," Journal of Biomolecular Screening, vol. 12, no. 1, pp. 100-105, 2007.

[14] Y. Yang, P. Gao, Y. Liu et al., "A discovery of novel Mycobacterium tuberculosis pantothenate synthetase inhibitors based on the molecular mechanism of actinomycin D inhibition," Bioorganic and Medicinal Chemistry Letters, vol. 21, no. 13, pp. 3943-3946, 2011.

[15] G. H. Dixon and H. L. Kornberg, "Assay methods for key enzymes of the glyoxylate cycle," Biochemical Journal, vol. 72, p. P3, 1959.

[16] S. M. Tripathi and R. Ramachandran, "Crystal structures of the Mycobacterium tuberculosis secretory antigen alanine dehydrogenase (Rv2780) in apo and ternary complex forms captures "open" and "closed" enzyme conformations," Proteins: Structure, Function and Genetics, vol. 72, no. 3, pp. 1089-1095, 2008.

[17] S. M. Tripathi and R. Ramachandran, "Overexpression, purification, crystallization and preliminary X-ray analysis of Rv2780 from Mycobacterium tuberculosis H37Rv," Acta Crystallographica Section F: Structural Biology and Crystallization Communications, vol. 64, no. 5, pp. 367-370, 2008.

[18] S. M. Tripathi and R. Ramachandran, "Overexpression, purification and crystallization of lysine $\mathcal{E}$-aminotransferase (Rv3290c) from Mycobacterium tuberculosis H37Rv," Acta Crystallographica F: Structural Biology and Crystallization Communications, vol. 62, no. 6, pp. 572-575, 2006.

[19] R. Adepu, K. S. Kumar, and S. Sandra, "C-N bond formation under Cu-catalysis: synthesis and in vitro evaluation of $N$-aryl substituted thieno[2,3-d]pyrimidin-4(3H)-ones against chorismate mutase," Bioorganic and Medicinal Chemistry, vol. 20, no. 17, pp. 5127-5138, 2012.

[20] G. Samala, P. B. Devi, R. Nallangi, P. Yogeeswari, and D. Sriram, "Development of 3-phenyl-4,5,6,7-tetrahydro- $1 H$ pyrazolo[4,3-c]pyridine derivatives as novel Mycobacterium tuberculosis pantothenate synthetase inhibitors," European Journal of Medicinal Chemistry, vol. 69, pp. 356-364, 2013.

[21] S. Wang and D. Eisenberg, "Crystal structures of a pantothenate synthetase from M. tuberculosis and its complexes with substrates and a reaction intermediate," Protein Science, vol. 12, no. 5, pp. 1097-1108, 2003.

[22] E. F. Pettersen, T. D. Goddard, C. C. Huang et al., "UCSF Chimera - a visualization system for exploratory research and analysis," Journal of Computational Chemistry, vol. 25, no. 13, pp. 1605-1612, 2004.

[23] O. Trott and A. J. Olson, "Software news and update AutoDock Vina: improving the speed and accuracy of docking with a new scoring function, efficient optimization, and multithreading," Journal of Computational Chemistry, vol. 31, no. 2, pp. 455-461, 2010.

[24] The PyMol Molecular Graphics System, "Version 1.1rl, Schrödinger, LLC," http://www.pymol.org. 

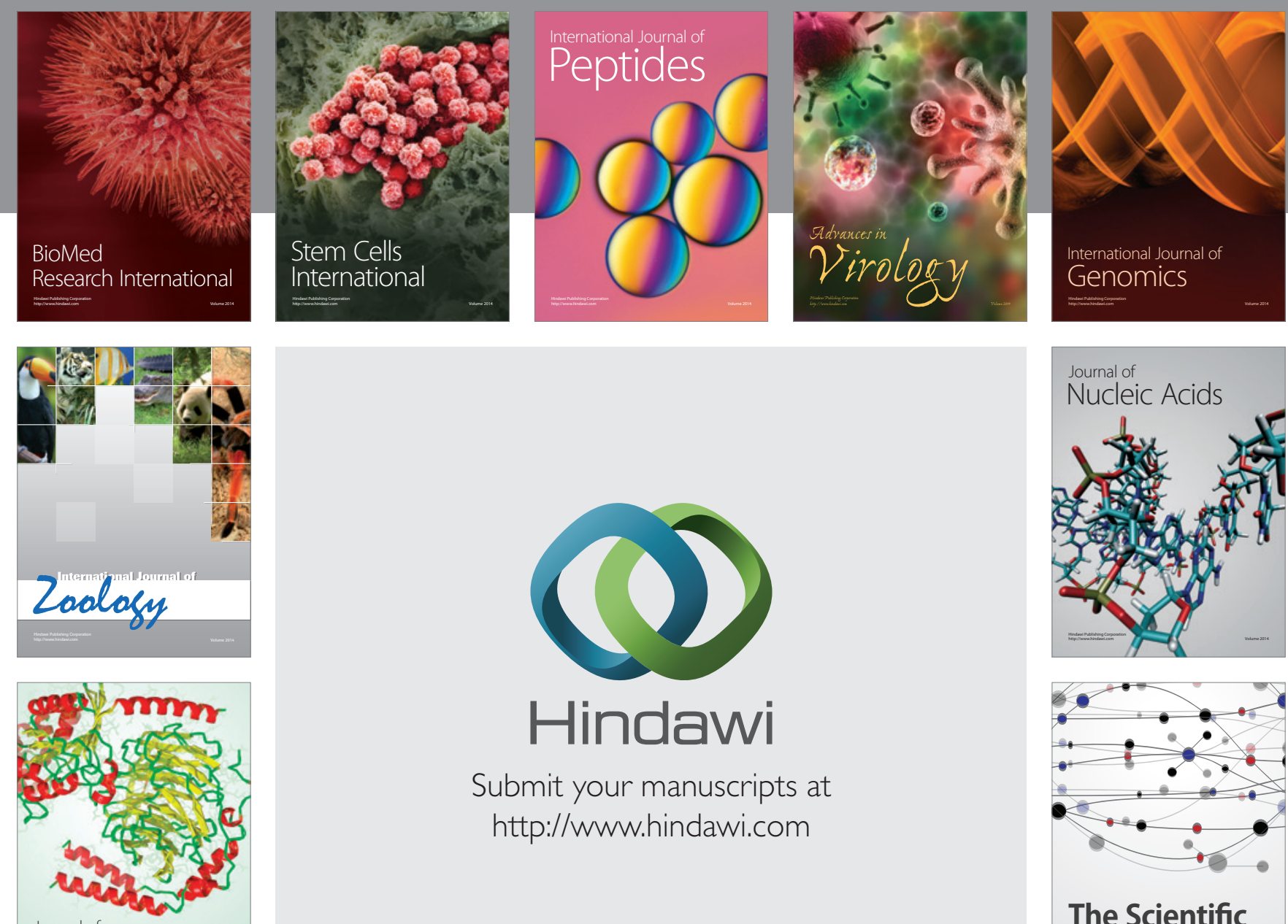

Submit your manuscripts at

http://www.hindawi.com

Journal of
Signal Transduction
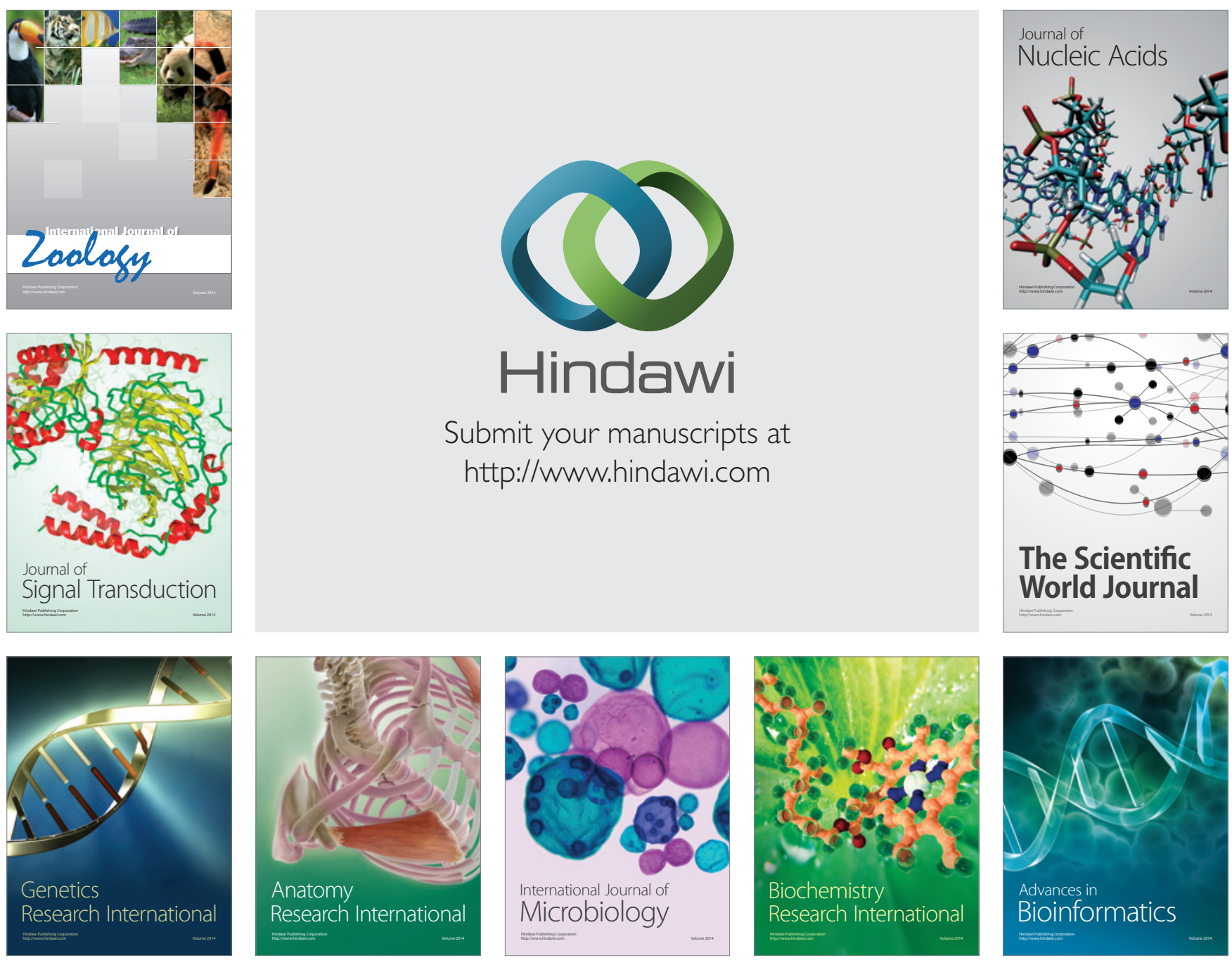

The Scientific World Journal
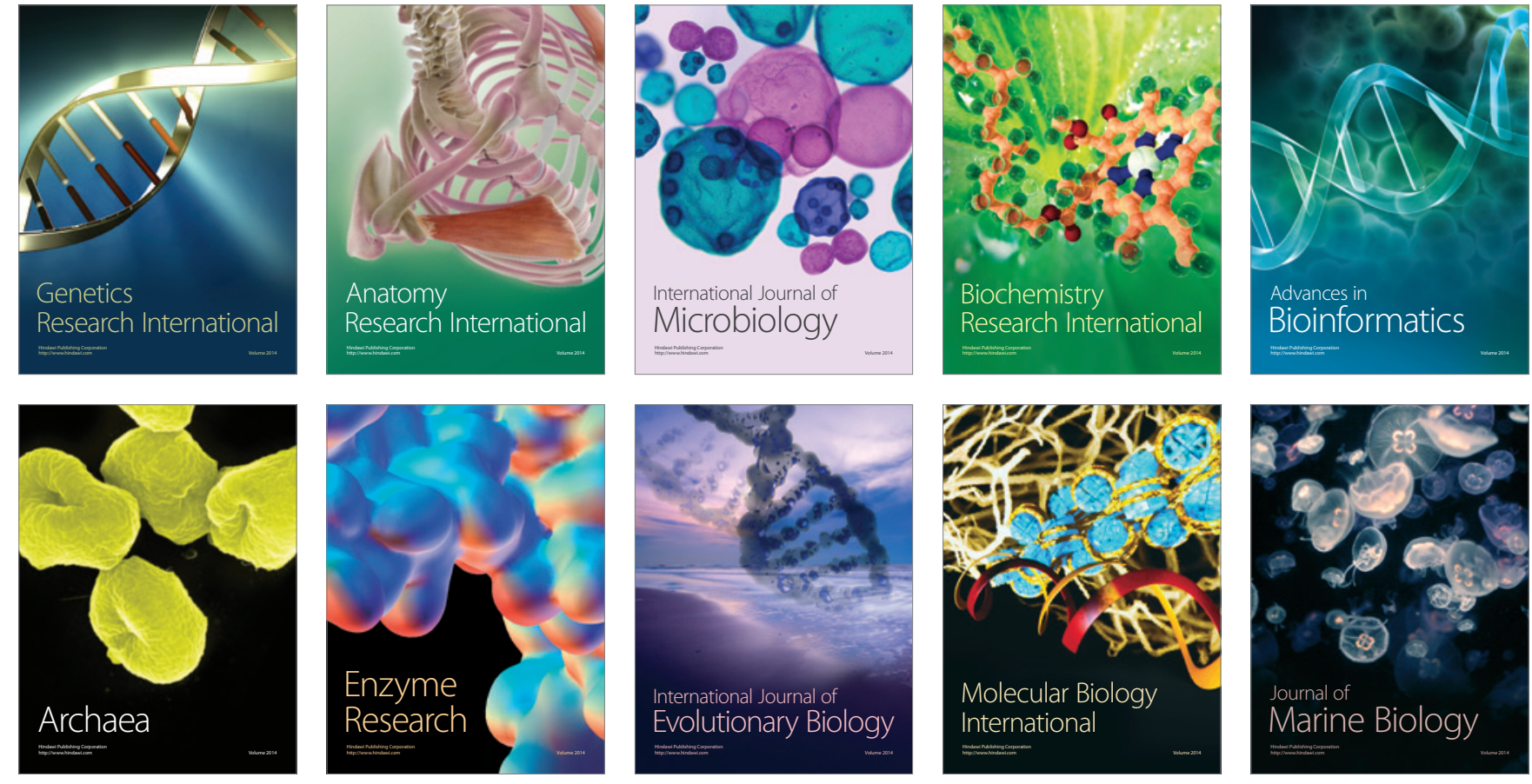